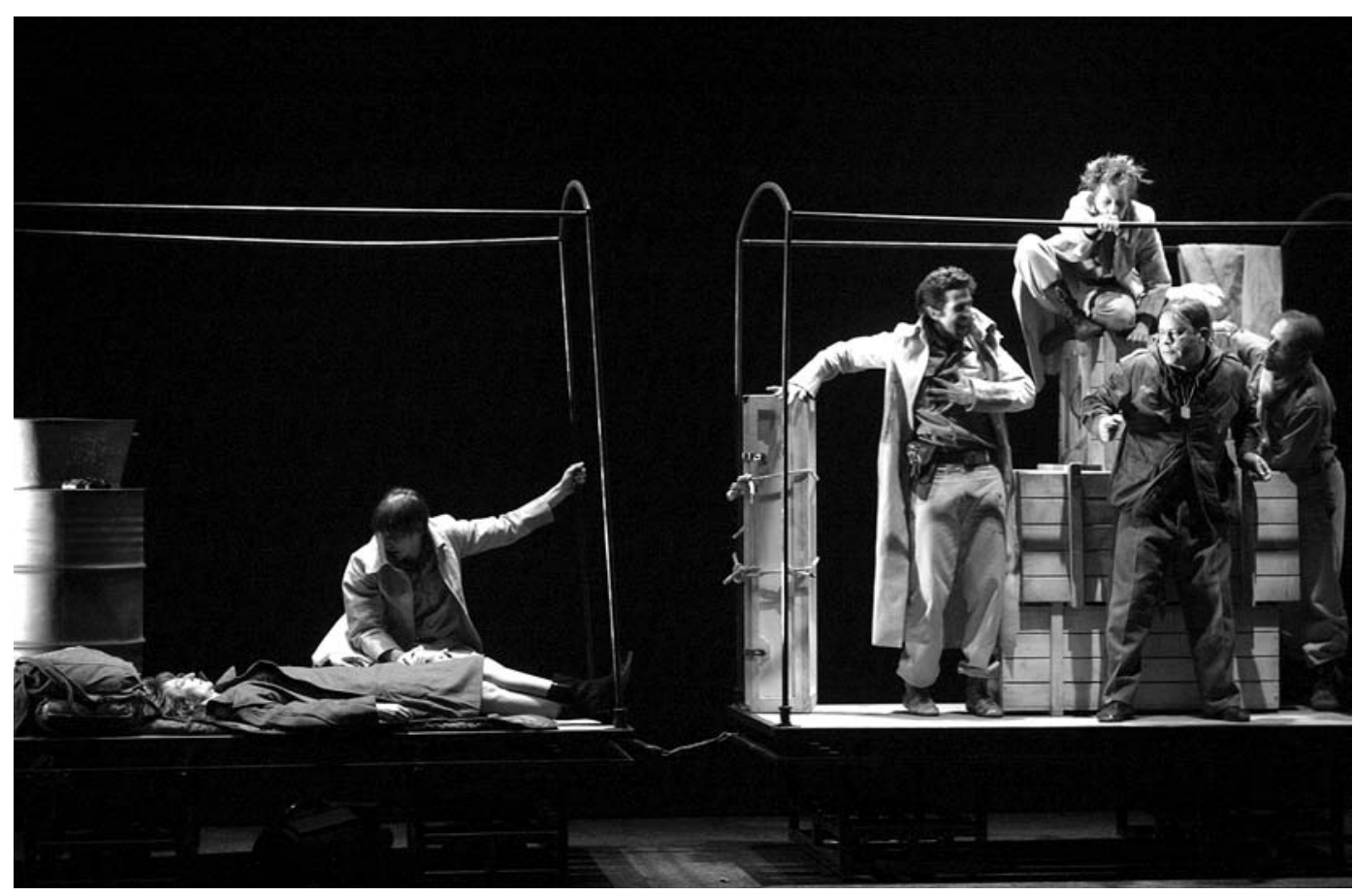

\title{
Homem = Homem? Brecht $=$ Brecht?
}

\section{Christine Zurbach}

Titulo: Homme pour homme (1926). Autor: Bertolt Brecht. Tradução: François Regnault. Encenação: Emmanuel Demarcy-Mota. Assistente de encenação: Christophe Lemaire. Cenografia e iluminação: Yves Collet. Colaboração cenográfica: Michel Bruguière. Som: Jefferson Lembeye e Walter N'Guyen. Figurinos: Corinne Baudelot. Música original (harpa): Bruno Mantovani. Maquilhagem: Catherine Nicolas. Adereços: Clémentine Aguettant. Consultora literária: Marie-Amélie Robilliard. Interpretação:Hugues Quester; Marie-Armelle Deguy; Phillipe Demarle; Charles-Roger Bour; Jauris Casanova; Sandra Faure; Stéphane Krähenbühl; Gérald Maillet; Sarah Karbasnikoff; Pascal Vuillemot; Laurent Charpentier e Constance Luzati (harpa). Produção: La Comédie de Reims - CDN / Théâtre de la Ville - Paris. Apoio: Culturesfrance. Apresentação em Lisboa: Teatro Nacional D. Maria II (Sala Garrett), 24 e 25 de Julho (no âmbito de MITE' 07. Mostra internacional de teatro).

Após uma primeira presença em Portugal em 2006 com Rinoceronte de lonesco incluído no programa da MITE' 06, a companhia francesa da Comédie de Reims, dirigida pelo encenador Emmanuel Demarcy-Mota, voltou a Lisboa em Julho deste ano, no âmbito da MITE' 07, trazendo o espectáculo Homme pour homme'. do dramaturgo alemão Bertolt Brecht. Numa parceria consolidada, também este ano, um espectáculo bilingue encenado por DemarcyMota, Tanto amor desperdiçado, com tradução de Nuno Júdice, juntou técnicos e artistas teatrais de Portugal e França, com digressões previstas nos dois paises. São dados que revelam um empenho crescente das instituições na busca de projectos internacionais, e reflectem também, neste caso, uma postura coerente por parte da companhia de Reims cujo programa artístico-teatral, de acordo com os materiais de promoção disponibilizados, segue "dois eixos: por um lado, [a insistência] do encenador (...) na formação de um colectivo de actores, autores e músicos, unidos por um projecto comum; por outro, [a promoção da] abertura da companhia às colaborações internacionais e à residência artística de outros grupos no espaço da
Comédie"2 além de investir na formação do público jovem. Para o espectador português ${ }^{3}$, a programação de uma peça como Homem por homem poderia ser considerada como uma infeliz redundância dos repertórios em cena, se a própria peça não fosse já um clássico da nossa modernidade. De facto, artistas e espectadores parecem voltar a ela com idêntica insistência, quer para aprofundar a sua decifração, quer para com ela progredir na compreensão de uma das fábulas brechtianas aparentemente mais simples na sua componente temática e, simultaneamente, mais complexa no seu tratamento cénico, do mesmo modo que o próprio Brecht a ela regressou várias vezes, adequando e ajustando o seu sentido, desde a versão inicial de 1926 até à encenação de 1953, de acordo com as mudanças que se sucediam no mundo. ${ }^{4}$

0 dramaturgista do espectáculo, François Regnault, fala da equação aritmética expressa pelo título, "homem = homem", para imediatamente a questionar e recorda: "Mas será que esta equação 'homem=homem' é mesmo verdadeira? Uma fábula brechtiana propõe-se primeiro
Homme pour homme de Bertolt Brecht, enc. Emmanuel Demarcy-Mota, Comédie de Reims - CDN I Théâtre de la Ville - Paris, 2007, fot. Jean-Louis Fernandez

10 espectáculo é intitulado Homem vale Homem no programa da MITE' 07 (p.18). A tradução dá conta da reflexão do dramaturgista François Regnault, também autor da tradução da peça para francês, que afirma: "em rigor, dever-se-ia traduzir Homem por homem por homem = homem, porque é a expressão de uma equação aritmética (o alemão utiliza o verbo 'ser' onde o francês diz 'é igual $\left.a^{\prime \prime \prime}\right)$.

${ }^{2}$ Ilbidem, p.20

${ }^{3}$ Em Portugal, a obra foi levada à cena, por ordem cronológica, no Teatro da Comuna (enc. João Mota, em 1978), no Centro

Dramático de Évora (enc. Luis Varela, em 1992) e no Teatro da Cornucópia (enc. Luis Miguel Cintra, em 2006).

${ }^{4}$ Ver a esse respeito as informações preciosas da investigadora Vera San Payo de Lemos para a edição portuguesa da peça: "No seu conjunto, todas estas versões reflectem o modo como Brecht foi reagindo às grandes transformações sociais e politicas ocorridas entre a Primeira e a Segunda Guerra Mundial" (in Brecht 2004: 17). 


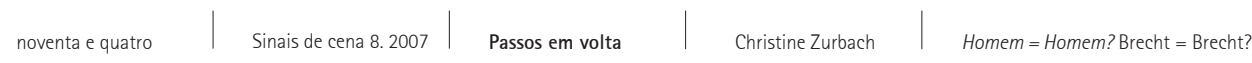

Homme pour homme,

de Bertolt Brecht,

enc. Emmanuel

Demarcy-Mota,

Comédie de Reims - CDN

I Thêâtre de la Ville - Paris,

2007,

fot. Jean-Louis Fernandez

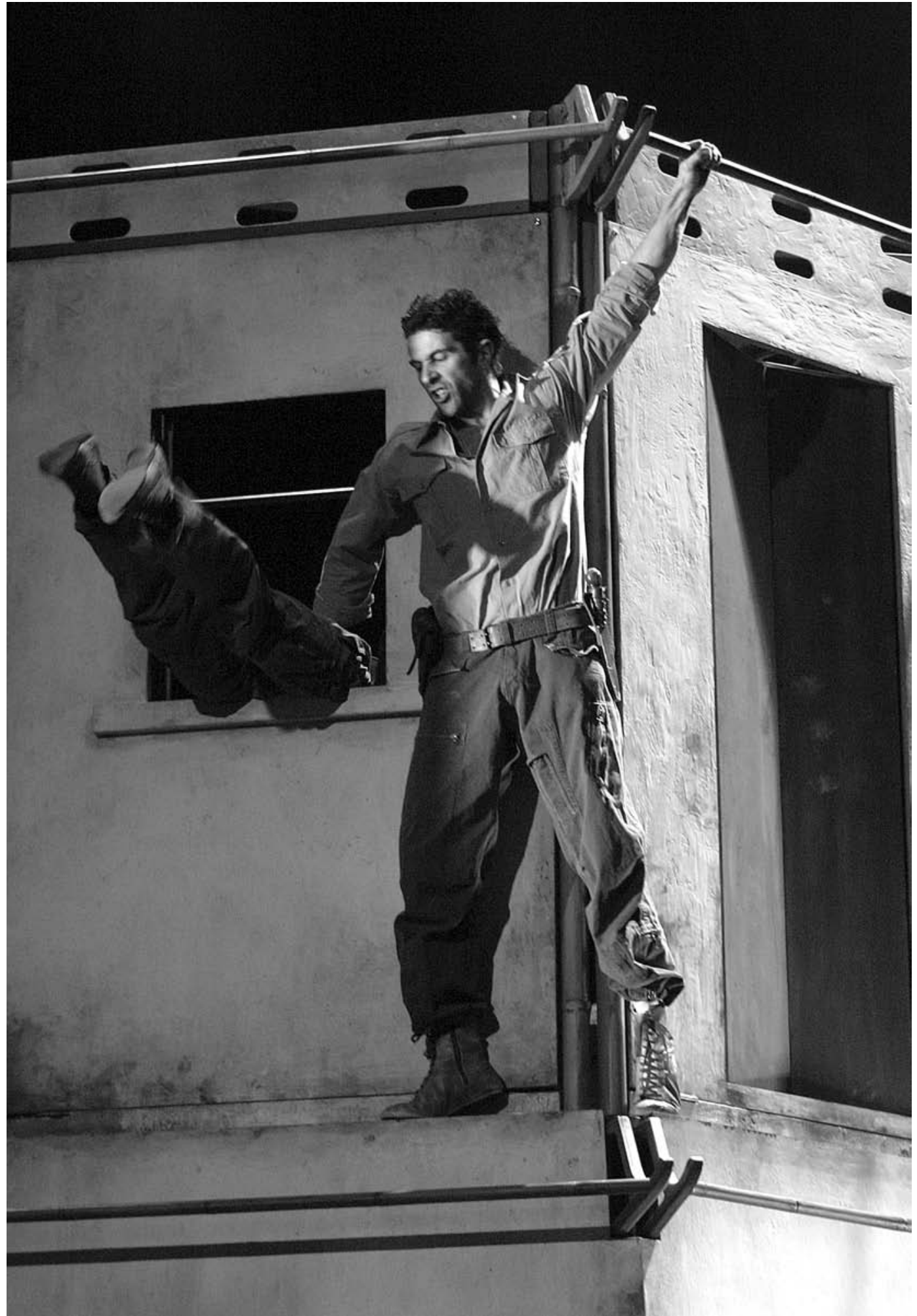

que tudo uma situação de que experimenta os impasses e as saídas (...) depois avança, vai, vem, bifurca-se, questiona-se a si própria, parece chegar a uma conclusão, mas cabe ao público dizer o que ela mostrou, ou até

${ }^{5}$ Cf. dossiê de dramaturgia elaborado por François Regnault e gentilmente cedido pela companhia. demonstrou" ${ }^{15}$. A orientação assim adoptada remete para o espectador a responsabilidade da construção do sentido e responsabiliza duplamente o encenador confrontado com uma peça considerada como (a mais) representativa da dramaturgia do teatro épico, portanto fortemente ligada à questão da sua "forma". De resto, essa é mais uma chave de leitura deixada pelo mesmo analista: "antes de saber o que a fábula diz, ou quer dizer, é preciso dizer o que ela conta"6 . Ou seja, definir a fábula desse "drama cómico" cuja construção se desenvolve em dois momentos distintos: a história de Galy Gay, deixando a sua casa para comprar um peixe no mercado e aceitando prestar um serviço aos soldados, seguida da demonstração metódica da sua transformação, com uma separação épica assumida pela personagem da viúva Begbick enquanto porta-voz do dramaturgo que refere explicitamente. 
Uma segunda chave importante para situar a leitura proposta por Demarcy-Mota encontra-se no Jornal do Teatro do TNDMII, onde o espectáculo Homme pour homme é descrito como "uma leitura contemporânea do texto de Brecht, considerado pela crítica como uma comédia anti-guerra", sendo uma peça que propõe ao espectador "uma reflexão sobre aquilo que [o encenador] designa de "novo tipo de homem", um homem construido, ou melhor, fabricado" . Com apoio na "actualidade do tema", oito décadas depois de a peça ter sido escrita, o encenador prossegue de certo modo o trabalho sistemático de reescrita da peça assumido pelo dramaturgo alemão de modo a promover leituras verdadeiramente contemporâneas do seu texto, em particular da questão sem resposta fora de um quadro histórico identificado: "quem é Galy Gay", aquele que diz de si próprio: "Acreditem em mim e não se riam, sou um homem que não sabe quem é. Mas esse Galy Gay não sou, isso eu sei. 0 que deve ser fuzilado, não sou eu. Mas quem é que eu sou?".

A consequência dessa opção é a escolha por parte do encenador de uma abordagem que privilegia a problemática da massificação do indivíduo, no contexto específico da condição militar actual, permitindo que a peça, agora alvo de uma nova interpretação, seja actualizada no sentido literal - ou seja, inscrita na nossa actualidade. Ficará por conseguinte por resolver a relação entre um texto assim privado de uma neutralidade própria do seu valor de demonstração, necessária à eficácia da teoria teatral que determinou a sua elaboração e cujo papel foi (e continua a ser) determinante nos debates sobre o papel do teatro na sociedade a partir da segunda metade do século XX.

0 resultado posto em cena mostra, de facto, que, para responder a tal intenção de aproximar o tema do nosso tempo, a proposta do encenador permitiu (ou necessitou de) uma valorização da dimensão psicológica da personagem protagonista da fábula, no trabalho interpretativo pedido ao actor. Na verdade, o mesmo documento de apresentação do espectáculo refere o carácter ambíguo da narração da transformação do pacífico estivador Galy Gay no guerreiro enraivecido Jeraiah Jip: "Ter-se-á Galy Gay deixado manipular ou, pelo contrário, estará a tirar proveito da situação? Será Jeraiah Jip uma personagem onde se refugiou ou terá, de facto, mudado? Onde reside a ambiguidade deste homem que não soube dizer não?"

Contrariamente à habitual frieza objectiva das leituras mais claramente inspiradas nas orientações brechtianas, geralmente propostas pelos encenadores dos últimos trinta ou quarenta anos, é nítida a preocupação de aproximar o espectador da problemática posta em cena. Assim, o ambiente militar e bélico, brutal e perigoso, no qual a acção se desenvolve apresenta-se como muito familiar para o nosso imaginário diariamente alimentado com a cinematografia e as reportagens televisivas - em particular no Iraque com as suas mulheres-soldados, para apenas citar os mais mediáticos... De acordo com as opções próprias de uma grande produção, e afastando-se do modelo épico original, mais elementar nos seus meios, o espaço é elaborado com cenários imponentes de grande volume e algum aparato técnico que se sucedem no palco aberto, em que o indivíduo isolado se dilui, apenas reconfortado pelo refúgio no grupo e seu anonimato. A cenografia leva o espectador para os lugares míticos da guerra, real ou de ficção, como o acampamento envolto numa luz pálida, ou o descampado hostil, num ambiente enublado, de lusco-fusco ou claro-escuro.

Preferencialmente estruturada em focos de luz vertical, com recortes nitidos ou de lado com imagens espectrais, a claridade sinistra que predomina deixa adivinhar uma maquilhagem nos rostos que privilegia a camuflagem como estratégia e como condição, ressaltando apenas a cor vermelha do sangue ou em adereços pontuais de grande significado. Também o elenco dos actores compõe um grupo alargado de soldados que multiplica e amplifica a situação do trio, acentuando a perda da individualização de Galy Gay progressivamente articulada com a massa anónima do regimento.

Se bem que conotada com dimensões próprias de montagens para grandes espectáculos, a encenação procurou não descuidar um recorte da progressão na demonstração proposta por Brecht, recorrendo a meios conhecidos da dramaturgia de estilo épico. Na nova tradução por François Regnault, a enunciação do texto surge cortante, o ritmo sem relevo da frase banal é privilegiado, com alguns efeitos quase rimados, úteis para uma quebra do naturalismo inerente ao conteúdo dos diálogos e das situações cénicas. Nesse plano, também, nota-se a importância dada à intervenção da música, fiel ao modelo épico, com execução da partitura original para harpa tocada ao vivo e inserida no decurso da acção em cena em momentos chave da acção. Outros meios são aproveitados, como o burlesco que pontua o jogo do actor-Galy Gay e o cómico da ida do sargento Blood Five ao wagon da viúva na noite da trovoada, ou o jogo circense no assalto ao pagode ou na cerimónia do chá no templo, ou o recurso à projecção, à voz offe à "Canção das coisas que passam", aos títulos no "negócio" do elefante...

Insistindo na singularidade do "caso Galy Gay", um indivíduo anódino que acabará por derrubar uma fortaleza do Tibete, o encenador produziu uma leitura que, retomando o questionamento lançado por Brecht, aproxima deliberadamente o espectador de problemáticas sombrias do nosso tempo, a do homem como número, explorado e perdido na massa ${ }^{9}$, mas simultaneamente se afasta do pessimismo da tradição criada em torno desse texto, revelando-se mais sensível à dimensão lúdica - e por isso, sábia - da dramaturgia de Brecht na sua estimulante e permanente capacidade de provocação.

Jornal do Teatro, TNDMII

13, Julho de 2007, Lisboa MITE' 07, Mostra Internacional de Teatro, p. 08

\section{Referência bibliográfica}

${ }^{8}$ Ibid., p.19.

BRECHT, Bertolt (2004), Teatro 2, Lisboa, Cotovia.

$$
{ }^{9} \text { Cf. n. } 2 .
$$

